\title{
The Effectiveness of Music Therapy on Hand Function in Patients With Stroke: A Systematic Review of Randomized Controlled Trials
}

\author{
Wen-Hao Huang ${ }^{1}$, Zu-Lin Dou ${ }^{1 *}$, Hui-Min Jin ${ }^{2}$, Ying Cui ${ }^{3}$, Xin $\mathrm{Li}^{1}$ and Qing Zeng ${ }^{4}$ \\ ${ }^{1}$ Third Affiliated Hospital of Sun Yat-sen University, Guangzhou, China, ${ }^{2}$ Shanghai Sunshine Rehabilitation Center, Shanghai, \\ China, ${ }^{3}$ Shandong University of Traditional Chinese Medicine, Jinan, China, ${ }^{4}$ Department of Rehabilitation Medicine, Zhujiang \\ Hospital of Southern Medical University, Guangzhou, China
}

OPEN ACCESS

Edited by:

Vida Abedi,

Geisinger Health System,

United States

Reviewed by:

Ingrid Poulsen,

Rigshospitalet, Denmark

Shima Shahjouei,

Geisinger Health System,

United States

*Correspondence:

Zu-Lin Dou

douzul@163.com

Specialty section: This article was submitted to

Stroke,

a section of the journal

Frontiers in Neurology

Received: 13 December 2020 Accepted: 06 April 2021

Published: 25 May 2021

Citation:

Huang W-H, Dou Z-L, Jin H-M, Cui Y, LiX and Zeng Q (2021) The

Effectiveness of Music Therapy on Hand Function in Patients With Stroke: A Systematic Review of

Randomized Controlled Trials.

Front. Neurol. 12:641023.

doi: 10.3389/fneur.2021.641023
Objective: This study aims to evaluate the efficacy of music-supported therapy for stroke patients' hand function.

Methods: The databases used included Cumulative Index to Nursing and Allied Health Literature (CINAHL), MEDLINE, PubMed, Embase, Music Index, and Google Scholar. Studies published between January 2010 and August 2020 were included. The searching key terms included "music-supported therapy," "music therapy," "hand function," "hand dysfunction," "stroke," "ischemic," and "hemorrhagic." Randomized controlled trials or controlled trials involving adults who have hand function problems caused by stroke are included in this study. The methodological quality and risk of bias of the included studies were rated by two independent assessors under the guidance of Cochrane collaboration's risk of bias tool.

Results: Twelve studies that met the inclusion criteria were included in this study. Totally, the data included 598 stroke patients (345 male, 253 female) with recruited time from 1.7 months to 3 years, and the mean age of the participants were 61.09 years old. Based on the Cochrane risk of bias tool, study quality ranged from three to seven out of seven points. Compared with the control group, outcomes including hand strength, range of joint motion, dexterity of hands, arm function, and quality of life were significantly superior with music-supported therapy. Five studies reported improved dexterity of hands, and one study reported the improvement of range of motion and strength of patients' hands, which supported the therapy has positive effects on patients' hand function and improving their quality of life after the therapy. The therapy ranged over a period of 4-8 weeks, with an average duration of $30 \mathrm{~min} / \mathrm{session}$ and an average of three times per week.

Conclusion: Based on the results, music-supported therapy could be a useful treatment for improving hand function and activities of daily living in patients with stroke, especially for patients within 6 months after stroke. However, the low certainty of evidence downgrades our confidence to practice in hospital. More and more randomized controlled trials and larger sample sizes are required for a deeper review.

Keywords: music supported therapy, hand function, stroke-diagnosis, systematic review, randomized controlled trial 


\section{INTRODUCTION}

Stroke is believed to affect more than two million patients annually in China and is one of the most common causes of hand function impairment in middle-aged as well as elderly people. The stroke symptoms may include numbness and weakness in the affected arms and cause a loss of coordination and dexterity $(1,2)$. Although most of the function can be restored with rehabilitation, ranging up to $79 \%$, the recovery of functional problems of the hand left after stroke is not as satisfactory (3). It has been estimated that $\sim 67 \%$ of stroke survivors are still unable to use the affected hand 4 years after the onset of stroke $(4,5)$. Therefore, rediscovering the potential of hand function and improving the quality of life is of great value to stroke patients.

The most commonly used conventional treatment for hand function problems include constraint-induced movement therapy (CIMT), mirror therapy, virtual reality, and musicsupported therapy (MST) (6-8). MST for hand function is usually achieved by playing the instructions. The movement patients conduct during playing the piano or grasping drumsticks can facilitate the coordination of hands, strengthen the power of grasp of the impaired hand (9). The aim of the MST is to improve the function of the upper limbs and to provide appropriate stimulation through real-time auditory feedback. Studies have shown that after a 4 -week MST program, the hand mobility, fluency, and speed of stroke patients can improve during the test. Besides, the sensory stimulation brought by music can induce functional recovery in damaged hemispheres.

Through the combination of music and movement, MST uses continuous movement and sensory input to enable the patient's central nervous system to re-establish new synaptic connections to the greatest extent possible, thereby creating new neuromotor pathways. Functional magnetic resonance imaging (fMRI) shows that the blood flow of the damaged area of the brain increases when receiving stimulation from MST, which can help repair the cerebral cortex caused by cerebral hemorrhage or cerebral infarction (10). Especially, when patients with high muscle tension caused by stroke, MST can relieve high muscle tension and increase the ability of fingers to move freely. Brain plasticity is associated with treatmentinduced recovery, which helps the patient to repair after the brain is damaged (11). When stroke patients participate in MST, they need to process information from multiple senses at the same time, including auditory, visual, and sensorimotor information, which is transmitted from the auditory system to the premotor cortex (PMC), thereby adjusting the topdown output (12). However, a major current focus in MST is to evaluate how does MST works and how does MST helps patients with gait problems (13). Few researchers have addressed the problem of MST improving the hand function of stroke patients.

Up to now, the effect of MST on the recovery of hand function during rehabilitation has not been gone through systematically yet. Therefore, we decided to undertake a systematic review to find out evidence that can support that MST has ideal curative effect in the recovery of impaired hand in stroke patients. The review sheds new light on the therapy for helping patients more effectively and increasing the ability of motor control, especially the hands so that they can finish the daily life task by themselves. One of the main challenges is that we need to search the randomized controlled trials (RCTs) based on MST on stroke patients, which are the gold standard for effectiveness research (14). Our systematic literature review solves the PICOS question, "Does MST can help stroke patients improve their hand function and increase the quality of life?" The answers may provide new thinking for occupational therapy and determine the effectiveness of the MST.

\section{METHODS}

This systematic review has been reported according to the Preferred Reporting Items for Systematic Review (PRISMA) statement. A protocol for this review was not registered prospectively.

\section{Search Strategy}

A systematic literature search of the following electronic databases was performed: Cumulative Index to Nursing and Allied Health Literature (CINAHL), MEDLINE, PubMed, Embase, Music Index, and Google Scholar. Databases were searched using a combination of the following keywords considering diagnose, therapy, and outcome. Diagnosis includes stroke, ischemic, and hemorrhagic. Exercise therapy includes music, rhythm, music therapy, MST, music movement therapy, neurologic music therapy (NMT), and neuroscience. The outcome includes neurologic assessment, physical and cognitive disability, strength and dexterity of the hands, gross mobility of hands, and the assessment of quality of life. MEDLINE was searched using $\mathrm{MeSH}$ headings which included dystonic disorders, neurofeedback/behavior therapy/exercise therapy, and recovery of function/treatment outcome. Additional articles were identified from reference lists of retrieved articles. The search was conducted in August 2020.

\section{Eligibility Criteria}

Studies were included if they met the following PICOS criteria:

(1) Population: The study population included adults (18 years old or older) diagnosed with ischemic or hemorrhagic stroke which was needed to be confirmed by computer tomography or magnetic resonance imaging and by diagnostic guidelines updated by the American Heart Association/American Stroke Association. The patients presenting with the FuglMeyer Assessment-upper extremity (FMA-UE) results less than 46 points.

(2) Intervention: Interventions had to be sound based, including music listening or listening to rhythmic sequences (MLI or RAS, which could be performed by various instruments, e.g., metronome, synthesizer). At least one group of participants had to perform a task in this condition.

(3) Controls: A similar motor act had to be performed without listening to music or rhythmic sequences (control intervention). 
(4) Outcome: Outcome measures had to assess hand function in a biomechanical manner (e.g., fine motor and gross mobility, strength and dexterity of the hands, functional movements of hands, muscle activity, or muscle-related assessment).

(5) Study design: All designs should be randomized controlled trials.

(6) Time: Articles published between January 2010 and August 2020.

Studies were excluded from a review when studies were not written in English and if less than half of the participants were musicians. In addition, altered auditory and sensory feedback strategies and studies assessing the combined effects of neuromuscular re-education and transcranial direct current stimulation were also excluded from the review.

\section{Study Selection}

The screening procedure was performed by two independent researchers. To collect potentially relevant studies, eligibility was screened based on title and abstract based on the provided inclusion and exclusion criteria described above. Full texts were retrieved and evaluated based on the same eligibility criteria. Afterward, full texts were gathered and evaluated on the previously set inclusion criteria. Reference lists were manually screened to identify additional relevant studies. Results between the two reviewers were compared, in situations where two reviewers were unable to come to an agreement, we took the original articles back together to solve the problem. See Figure 1.

\section{Data Extraction and Analysis}

Data were extracted and documented using an extraction form developed to identify relevant information. Details recorded from each reference included the author's background and discipline, participants, intervention (follow-up), control/comparison, outcome measures, and results. Data and information were extracted by one reviewer and checked for accuracy by a second reviewer. The patients' characteristics and intervention detail of each study were summarized in Table 1, reflecting the heterogeneity of the included studies.

The risk of bias assessment was based on the handbook of Cochrane (5.1 version). To assess bias, two reviewers independently followed the steps to choose low risk and high risk; if a question was impossible to answer because the original article did not specify it or it was unclear, we chose "unclear." Reviewers assessed selection (random sequence generation and allocation concealment), performance (blinding of participants and personnel), detection (blinding of outcome assessors), attrition (incomplete outcome data), reporting (selective reporting), and other sources of bias. If there is a disagreement between two reviewers, a third reviewer will solve it. See Figures 2, 3.

\section{RESULTS}

\section{Study Characteristics}

In order to identify the review, a total of 269 articles were retrieved in this search. Two hundred twelve articles were

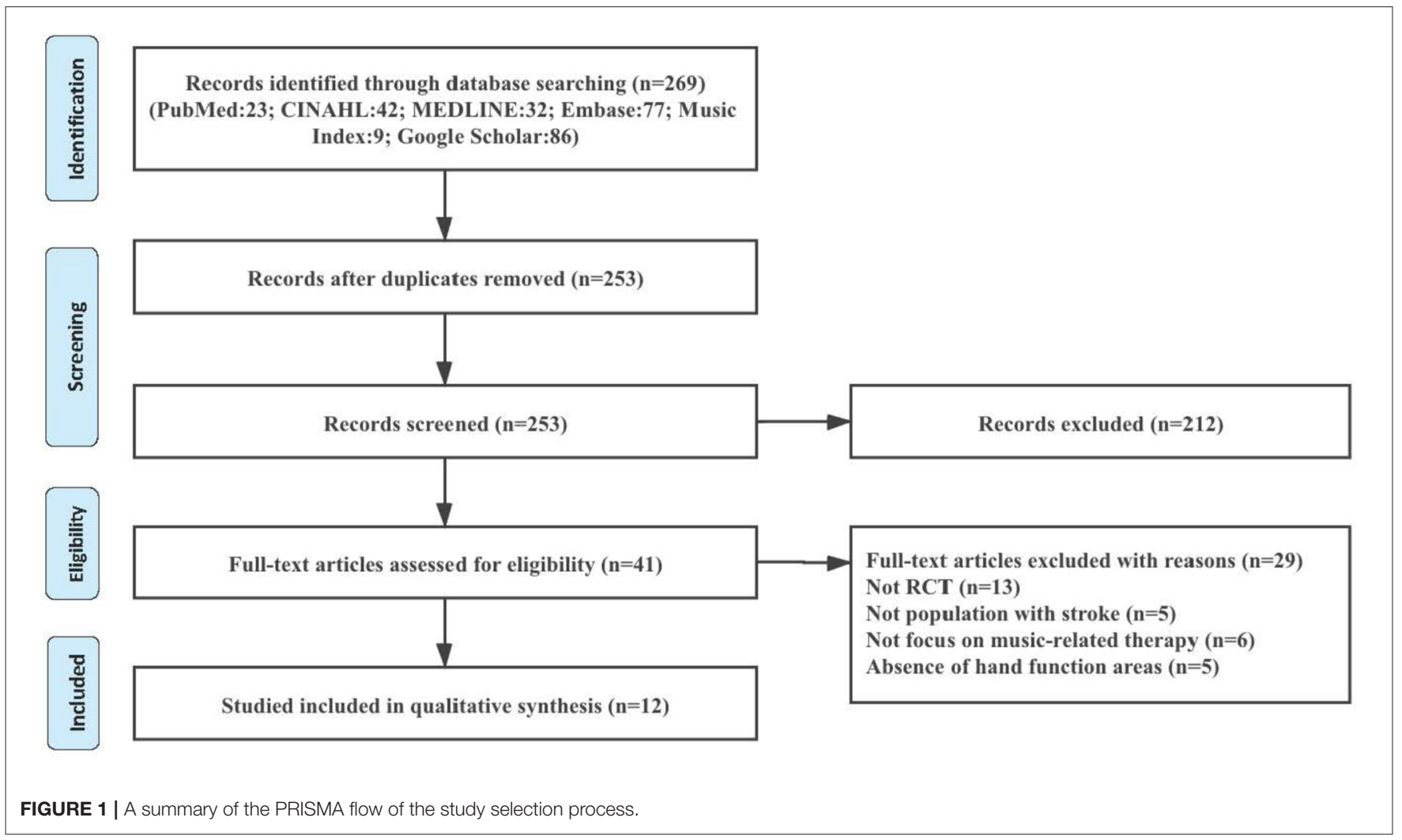


TABLE 1 | Summary of the included studies and the detail of intervention and measurement.

\begin{tabular}{|c|c|c|c|c|c|}
\hline Reference & Participants & Intervention (follow-up) & Control/comparison & Outcome measures & Results \\
\hline Raglio et al. (15) & $\begin{array}{l}N=38 \\
\text { age range: } 54-89\end{array}$ & $\begin{array}{l}\text { The standard of care and } \\
\text { relational active music } \\
\text { therapy approach ( } n=19) \\
\text { Repeat exercise: } 20 \\
\text { sessions lasting } 30 \text { min } \\
\text { each, 3-weekly }\end{array}$ & $\begin{array}{l}\text { Only standard of care, } \\
\text { including physiotherapy } \\
\text { and occupational } \\
\text { therapy }(n=19)\end{array}$ & $\begin{array}{l}\text { Measured at baseline and at the } \\
\text { end of treatment } \\
\text { Neurologic: It-NIHSS } \\
\text { Physical and cognitive disability: } \\
\text { FIM } \\
\text { Strength/dexterity of the hands: } \\
\text { the Grip-Pinch Dynamometric } \\
\text { Test and the Nine-hole Peg Test } \\
\text { Gross mobility: TUG } \\
\text { Psychological traits and quality } \\
\text { of life: HADS and MQOL-It } \\
\text { Video-recorded sessions: MTRS }\end{array}$ & $\begin{array}{l}\text { Neurologic: no significant difference } \\
\text { between groups } \\
\text { Physical and cognitive disability: } \\
\text { improved both in experimental and } \\
\text { control groups ( } p=0.001) \\
\text { Strength/dexterity of the hands: the } \\
\text { amount of left paretic patients ( } n=5) \\
\text { improved more than control groups } \\
(n=2) \\
\text { Gross mobility: improved both in } \\
\text { experimental and control groups } \\
\text { ( } p=0.032) \\
\text { Psychological traits and quality of life: } \\
\text { a decrease of anxiety and depression } \\
\text { and a significant positive trend }\end{array}$ \\
\hline Street et al. (16) & $\begin{array}{l}N=11 \\
\text { age range: } 53-67\end{array}$ & $\begin{array}{l}\text { Play acoustic musical } \\
\text { instruments and/or iPads } \\
\text { with touch screen musical } \\
\text { instruments ( } n=6) \\
\text { Repeat exercise: } 20-30 \text { min } \\
\text { a session, twice weekly for } \\
6 \text { weeks }\end{array}$ & $\begin{array}{l}\text { Received no } \\
\text { intervention }(n=5)\end{array}$ & $\begin{array}{l}\text { Measured at baseline and at 6-, } \\
\text { 9-, 15-, and 18-week follow-up } \\
\text { Arm function: the action research } \\
\text { arm test and the 9-hole peg test }\end{array}$ & $\begin{array}{l}\text { Arm function: no significant difference } \\
\text { between groups }\end{array}$ \\
\hline Street et al. (9) & $\begin{array}{l}N=14 \\
\text { age range: } 18-90\end{array}$ & $\begin{array}{l}\text { Therapeutic instrumental } \\
\text { music performance therapy } \\
(n=7) \\
\text { Repeat exercise: twice } \\
\text { weekly for } 6 \text { weeks }\end{array}$ & $\begin{array}{l}\text { Received no } \\
\text { intervention }(n=7)\end{array}$ & $\begin{array}{l}\text { Measured at baseline and at 6-, } \\
\text { 9-, 15-, and 18-week follow-up } \\
\text { Arm function: the action research } \\
\text { arm test and the 9-hole peg test } \\
\text { Electroencephalography } \\
\text { Recording }\end{array}$ & $\begin{array}{l}\text { Arm function: no significant difference } \\
\text { between groups } \\
\text { Electroencephalography recording: } \\
\text { no significant difference } \\
\text { between groups }\end{array}$ \\
\hline $\begin{array}{l}\text { Grau-Sanchez } \\
\text { et al. (17) }\end{array}$ & $\begin{array}{l}N=39 \\
\text { age range: } 54-92\end{array}$ & $\begin{array}{l}\text { The regular therapy and } \\
\text { extra sessions to play a } \\
\text { keyboard and an electronic } \\
\text { drum set ( } n=20) \\
\text { Repeat exercise: } 20 \\
\text { individual sessions, } 30 \text { min } \\
\text { each, } 5 \text { sessions/week for } \\
4 \text { weeks }\end{array}$ & $\begin{array}{l}\text { Extra time for exercises } \\
\text { for the upper extremity } \\
\text { based on the regular } \\
\text { therapy }(n=20)\end{array}$ & $\begin{array}{l}\text { Measured at baseline, after the } \\
\text { intervention, and at a 3-month } \\
\text { follow-up } \\
\text { Functional movements: the } \\
\text { action research arm test } \\
\text { Motor outcomes: FMA and grip } \\
\text { strength } \\
\text { Fine dexterity: the 9-hole peg } \\
\text { test and BBT } \\
\text { Activities of daily living: CAHAl } \\
\text { Working memory and attention: } \\
\text { the digit span subtest from the } \\
\text { Wechsler Adult Intelligence Scale } \\
\text { III, response inhibition by the } \\
\text { Stroop task and processing } \\
\text { speed and mental flexibility by } \\
\text { the trail-making test } \\
\text { Verbal memory: RAVLT and the } \\
\text { story recall from the Rivermead } \\
\text { behavioral memory test } \\
\text { Mood outcomes: the Profile of } \\
\text { Mood States, the Beck } \\
\text { Depression Inventory Scale, the } \\
\text { Positive and Negative Affect } \\
\text { Scale, and the Apathy Evaluation } \\
\text { Scale. } \\
\text { QoL outcomes: the } \\
\text { Stroke-Specific QoL Scale and } \\
\text { health-related QoL with the } \\
\text { health survey } \\
\text { questionnaire SF36. }\end{array}$ & $\begin{array}{l}\text { Functional movements: significantly } \\
\text { improved functional performance } \\
\text { score in the MST group compared } \\
\text { with CT group (mean } \pm \mathrm{SD} \text {, standard } \\
\text { treatment with exercise, } 9.8 \pm 7.9, \\
\text { vs. exercise, } 6.7 \pm 7.9 ; p<0.001 \text { ) } \\
\text { Motor outcomes: no significant } \\
\text { difference between groups } \\
\text { Fine dexterity: no significant } \\
\text { difference between groups } \\
\text { Activities of daily living: no significant } \\
\text { difference between groups } \\
\text { The cognitive outcomes: no } \\
\text { significant difference between groups } \\
\text { QoL outcomes: significantly improved } \\
\text { in the MST group from baseline to } \\
\text { posttreatment compared with CT } \\
\text { group (MST group of } t_{(18)}=-2.23 \text {, } \\
p<0.05, d=0.54 \text { vs. CT group of } \\
\text { no improvements) } \\
\text { Mood outcomes: no significant } \\
\text { differences between groups in the } \\
\text { change scores }\end{array}$ \\
\hline
\end{tabular}


TABLE 1 | Continued

\begin{tabular}{|c|c|c|c|c|}
\hline Reference & Participants & Intervention (follow-up) & Control/comparison & Outcome measures \\
\hline Jun et al. (18) & $\begin{array}{l}N=30 \\
\text { age range: } 54-93\end{array}$ & $\begin{array}{l}\text { Received music and } \\
\text { movement therapy }(n=15) \text {. } \\
\text { Repeat exercise: } \\
1 \mathrm{~h} / \text { session, } 3 \text { times/week } \\
\text { for } 8 \text { weeks }\end{array}$ & $\begin{array}{l}\text { Received routine } \\
\text { care }(n=15)\end{array}$ & $\begin{array}{l}\text { Measured at baseline and at } \\
\text { 8-week follow-up } \\
\text { Physical functions: range of joint } \\
\text { motion } \\
\text { Muscle strength: Medical } \\
\text { Research Council scale } \\
\text { Activities of daily living: K-MBI } \\
\text { Mood state: the Korean version } \\
\text { of the Profile of Mood States } \\
\text { Brief instrument } \\
\text { Depression: CES-D }\end{array}$ \\
\hline
\end{tabular}

Van Vugt et al. $\quad N=34$;

(19)

age range: $30-75$

Received its sounds after a Received the its random delay sampled from sounds immediately a flat distribution between 100 and $600 \mathrm{~ms}$ when the patients play the piano ( $n=19)$

Repeat exercise: 10 sessions of half an hour when the patients play the piano $(n=15)$
Measured at baseline, after the intervention

Fine motor control: the 9-hole peg test

Finger tapping measurements: triaxial accelerometer (ADXL 335)

Mood measurements: POMS
Results

Physical functions: no significant difference between groups Muscle strength: no significant difference between groups Activities of daily living: no significant difference between groups Mood state: the score of experimental group members improved when compared with that of the contro group ( $t=1.818, p=0.040$ ) Depression: no significant difference between groups

Fine motor control: significantly improved fine motor score in the jitter group compared with normal group (mean $\pm \mathrm{SD}$, the average improvement of jitter group,

$14 \pm 53.6$ vs. normal, $3.8 \pm 17.9$ $p<0.001)$

Tapping speed: no significant difference between groups Tapping variability: no significant difference between groups Mood measurements: no significant difference between groups

Cognitive deficits: significantly improved cognitive score in the recovery group compared with no-recovery group (mean $\pm \mathrm{SD}$, the recovery group, $26.38 \pm 1$ vs. no-recovery group, $24.33 \pm 2$; $p<0.001$ ) Performance in activities of daily living: significantly improved ADL score in the recovery group compared with no-recovery group (mean $\pm \mathrm{SD}$, the recovery group, $81.92 \pm 2$ vs. no-recovery group, $76.53 \pm 7 ; p=0.007$ ) CT perfusion: significantly improved in $\mathrm{CBF}$ in affected area in the recovery group compared with no-recovery group (mean $\pm \mathrm{SD}$, the recovery group, $29.16 \pm 4$ vs. no-recovery group, $12.27 \pm 11 ; p<0.001$ )

Hand strength: significant differences in the mean changes in right-sided maximum and left-sided final grip force Rhythm-and-music group significantly improved their right-sided maximum grip force(16.41 [95\% Cl,

5.65-27.17]) and left-sided final grip force (17.26 [95\% Cl, 6.19-28.33]) compared with controls $(-1.29$ [95\% $\mathrm{Cl},-7.99$ to 5.41$])(0.55$ [95\% Cl, -7.07 to 8.17$] ; p=0.015$ and 0.042 , respectively);

The left-sided improvements were sustained at the 6-month follow-up $(p=0.011)$. 
TABLE 1 | Continued

\begin{tabular}{|c|c|c|c|c|c|}
\hline Reference & Participants & Intervention (follow-up) & Control/comparison & Outcome measures & Results \\
\hline Tong et al. (12) & $\begin{array}{l}N=33 \\
\text { age range: } \\
34-64.9\end{array}$ & $\begin{array}{l}\text { Audible music group (MG) } \\
\text { includes conventional } \\
\text { rehabilitation treatments and } \\
\text { extra sessions of audible } \\
\text { musical instrument training } \\
(n=15) \\
\text { Repeat exercise: } 20 \text { extra } \\
\text { sessions over } 4 \text { weeks }\end{array}$ & $\begin{array}{l}\text { Mute music group (CG) } \\
\text { includes conventional } \\
\text { rehabilitation } \\
\text { treatments and extra } \\
\text { sessions of "mute" } \\
\text { musical instrument } \\
\text { training ( } n=18 \text { ) } \\
\text { Repeat exercise: } 20 \\
\text { extra sessions } \\
\text { over } 4 \text { weeks }\end{array}$ & $\begin{array}{l}\text { Measured at baseline, after the } \\
\text { intervention } \\
\text { Motor function: WMFT, FMA }\end{array}$ & $\begin{array}{l}\text { Motor functions of upper limbs: } \\
\text { significant improvements } \\
\text { Significant differences in the WMFT } \\
\text { were found between the two groups } \\
\text { (WMFT-quality: } p=0.025 \text {; } \\
\text { WMFT-time: } p=0.037 \text { ) but not in the } \\
\text { FMA ( } p=0.448 \text { ). } \\
\text { Subjects in MG demonstrated greater } \\
\text { improvement than those in CG. }\end{array}$ \\
\hline $\begin{array}{l}\text { Schneider et al. } \\
(22)\end{array}$ & $\begin{array}{l}N=77 \\
\text { age range: } \\
41.2-68\end{array}$ & $\begin{array}{l}\text { Music-supported therapy in } \\
\text { addition to conventional } \\
\text { therapy ( } n=32) \text {. } \\
\text { Repeat exercise: } 30 \text { min } \\
\text { each unit in duration, totally } \\
27.4 \text { units, over } 3 \text { weeks }\end{array}$ & $\begin{array}{l}\text { Conventional treatment } \\
\text { only }(n=30) \text {, Without } \\
\text { specific additional } \\
\text { selection criteria } \\
(n=15) \text { standard } \\
\text { therapies (physical } \\
\text { therapy and individual } \\
\text { occupational therapy) } \\
30 \text { min each unit in } \\
\text { duration. } \\
\text { TG: } 28.0 \text { units over } \\
3 \text { weeks } \\
\text { CG: } 27.2 \text { units } \\
\text { over } 3 \text { weeks }\end{array}$ & $\begin{array}{l}\text { Measured at baseline, 3-week } \\
\text { intervention } \\
\text { Motor functions: BBT, the 9-hole } \\
\text { peg test, action research arm } \\
\text { test, arm paresis score } \\
\text { Motor test/parameter: frequency } \\
\text { (FREQ), Number of inversions of } \\
\text { velocity profiles, Average } \\
\text { maximum angular velocity in \% } / \mathrm{s}\end{array}$ & $\begin{array}{l}\text { BBT, the 9-hole peg test, action } \\
\text { research arm test, and arm paresis } \\
\text { score: significant improvements in } \\
\text { groups TG and MG. Conventional } \\
\text { physiotherapy in CG did not produce } \\
\text { an improvement, differences between } \\
\text { MG, CG, and TG were highly } \\
\text { significant, } F(2,66)=6.66 \text {, } \\
p=0.002 \text {. } \\
\text { BBT: MG increased the number of } \\
\text { cubes grasped by around 10/min. } \\
\text { Differences between MG, CG, and } \\
\text { TG were highly significant, } \\
\text { F(2,74) }=57.08, p<0.001 \text {. } \\
\text { FREQ: Increase in MG but not TG } \\
\text { and CG }\end{array}$ \\
\hline Fujioka et al. (23) & $\begin{array}{l}N=29 \\
\text { age range: } \\
54.3-64.2\end{array}$ & $\begin{array}{l}\text { Music-supported therapy } \\
\text { used an electronic keyboard } \\
\text { and a series of eight } \\
\text { electronic drum pads } \\
\text { ( } n=14) \text {. } \\
\text { Repeat exercise: } 30 \text { h of } \\
\text { training over } 10 \text { weeks }\end{array}$ & $\begin{array}{l}\text { Conventional physical } \\
\text { training }(n=14) \\
\text { Repeat exercise: } 30 \mathrm{~h} \\
\text { of training } \\
\text { over } 10 \text { weeks }\end{array}$ & $\begin{array}{l}\text { Measured at baseline, after } \\
5 \text { weeks, after } 10 \text { weeks, and } \\
3 \text { months after training } \\
\text { completion. } \\
\text { Arm and hand subsections of the } \\
\text { CMSA Impairment Inventory, } \\
\text { action research arm test, BBT }\end{array}$ & $\begin{array}{l}\text { CMSA: Both showed only minor } \\
\text { changes over the time course of } \\
\text { treatment, hand score was improved } \\
\text { at the post } 2 \text { time point compared } \\
\text { with pre }\left[t_{(27)}=-2.27, p=0.031\right] \text {. } \\
\text { A tendency for such improvement } \\
\text { was found for the MST group } \\
\text { [t(13) }=-1.88, p=0.082] \text {. The } \\
\text { improvement in the GRASP group } \\
\text { was not significant. } \\
\text { Action research arm test: in the MST } \\
\text { group, the decrease between pre and } \\
\text { post } 2 \text { time points approached } \\
\text { significance }\left[t_{(13)}=2.10, p=0.056\right] \text {. } \\
\text { BBT: not to analyze, as eight } \\
\text { participants were unable to perform } \\
\text { the test at any time point using their } \\
\text { affected hand. }\end{array}$ \\
\hline $\begin{array}{l}\text { Bunketorp-Käll } \\
\text { et al. (24) }\end{array}$ & $\begin{array}{l}N=123 \\
\text { age range: } \\
56-70.4\end{array}$ & $\begin{array}{l}\text { Rhythm-and-music therapy } \\
(n=41) \\
\text { Horse-riding therapy } \\
(n=41) \\
\text { Repeat exercise: } 2 \text { times a } \\
\text { week for } 12 \text { weeks. }\end{array}$ & $\begin{array}{l}\text { Control group continue } \\
\text { with their regular } \\
\text { activities and usual } \\
\text { care such as outpatient } \\
\text { physiotherapy, } \\
\text { occupational therapy, } \\
\text { or speech } \\
\text { therapy }(n=41) \text {. }\end{array}$ & $\begin{array}{l}\text { Measured at baseline, after the } \\
\text { intervention } \\
\text { Motor function: Modified Motor } \\
\text { Assessment Scale. }\end{array}$ & $\begin{array}{l}\text { Modified Motor Assessment Scale: } \\
\text { The MST group did not produce any } \\
\text { immediate gains. } 6 \text { months } 31 \\
\text { post-intervention, the MST group } \\
\text { performed better with respect to time; } \\
-0.75 \text { s [ } 95 \% \mathrm{Cl},-1.36 \text { to } \\
-0.14] ;(p=0.035)\end{array}$ \\
\hline
\end{tabular}

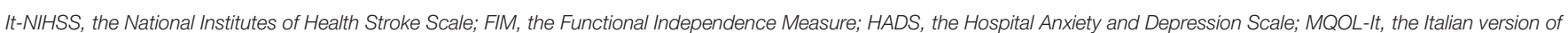

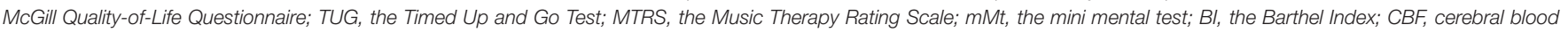

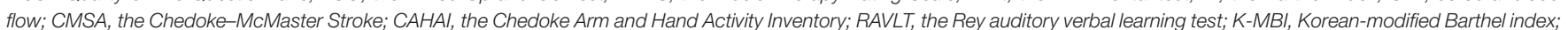

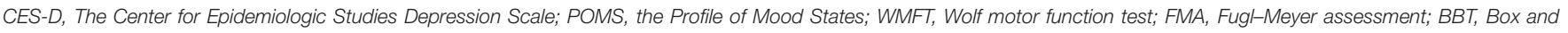
Block test.

considered for screening, and 41 full-text articles were excluded because the study did not focus on the stroke patients $(n=5)$, the type of study did not meet our inclusion criteria $(n=13)$, the abstract of study did not focus on the music-supported therapy $(n=6)$, and hand function areas $(n=5)$. Twelve articles were included in the systematic review. See Table 1. 


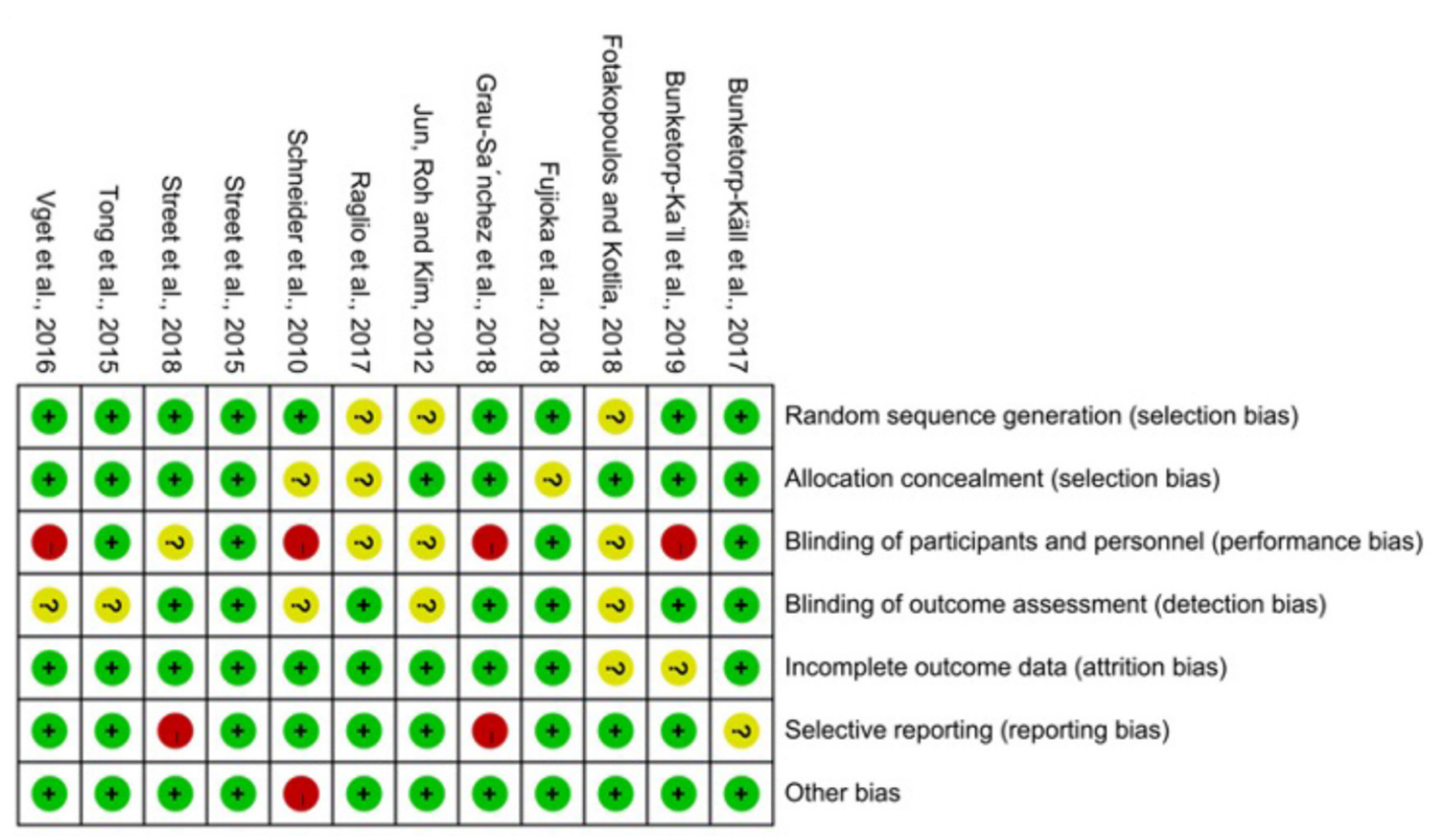

FIGURE 2 | Risk of bias summary.

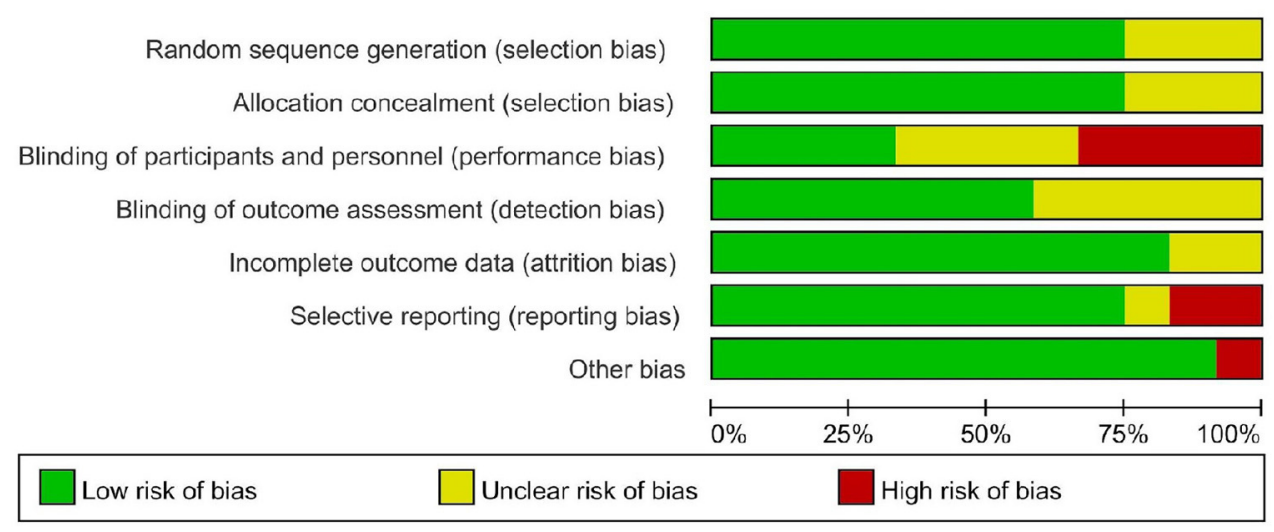

FIGURE 3 | Risk of bias graph.

\section{Baseline of Patients}

Totally, the data involved 598 stroke patients of mixed gender population. The included studies had the gender distribution as follows: 253 females and 345 males. The mean age of the participants was 61.09 years old $(\mathrm{SD}=11.43)$, ranging from 48.6 to 76.02 years old $(9,12,16,17,19,21-$ 24). All subjects suffered from stroke from 1.7 months to 3 years before exposed to the MST intervention. Four articles did not provide the time of poststroke of the population in their articles. Based on the data of demographics, the percentage of ischemic stroke was $74.53 \%$ (199 participants) and the percentage of hemorrhagic stroke was $25.47 \%$ (68 participants).

\section{Risk of Bias of Included Studies}

The items' random sequence generation, allocation concealment, incomplete outcome data, and other sources of bias were assessed as low risk of bias in most of the included studies $(9,12,16$, 17, 19, 21-24). Blinding of participants and personnel scored high risk of bias or unclear risk in half of the included studies, which is inherent to the intervention $(15-20,22,24)$. There are some studies that the blinding of outcome assessment was not 
described clearly so that they were scored unclear in the detection bias $(12,19,20,22)$.

\section{Intervention Characteristics}

Study objectives varied greatly; music was used to influence grip strength $(15,17,18,21)$, range of joint motion (18), dexterity of the hands $(9,15-17,19,22)$, and arm function $(9,12,16,17,22-$ $24)$, and demonstrated the changes of activities of daily living (17, $18,20)$ and quality of life $(15,17,23)$. To determine effectiveness, musical interventions were compared with blank control group $(9,16)$, standard of care, regular activities $(15,18,20,21,23)$, conventional rehabilitation treatments $(12,17,22,24)$, and mute music training $(19,24)$. Conventional rehabilitation treatments such as passive mobilization, stretch and progressive resistance exercises, and task-specific training $(17,22)$, mute music training such as using a sponge or custom-made pad on the musical instrument to inhibit or delay patients from hearing sounds during the training $(19,24)$.

Nine trials required participants played rhythmical-melodic musical instruments or digital music equipment, such as xylophones, glockenspiels, drums, bongos, ethnic percussion, piano, iPads with touch screen musical instruments $(9,12,15-$ 19, 22, 23). The methods included free interactions between patients and music therapists and sang a song while playing musical instruments. Three trials employed prepared music and daily listening to experiential/traditional music (20, 21, 24); two of three trials involved structured R-MT combining listening to music while performing coordinated rhythmic sequences and cognitively $(21,24)$. Participants were trained to begin with motions of the unaffected side and then the affected upper extremity following a modular therapy regime with a stepwise increase of complexity $(17,18)$.

Sessions were offered one-to-one with individual participants at home or clinical setting $(9,12,16,17,19,22,23)$ or to small groups $(15,18,20,21,24)$. Within these sessions, there was consistent treatment "dosage," lasting a single session of 30 or $45 \mathrm{~min}$ each. The duration of interventions was variability ranging from 20 sessions over 3 weeks (15) to four sessions weekly over 6 months (20). Delivery of musical interventions was predominantly provided by experienced music therapists or licensed therapists.

\section{Qualitative Synthesis: Outcome}

The included articles show that MST has a better effect on stroke patients in the acute and recovery phases when compared with the group that received conventional rehabilitation. The effect on stroke patients includes many aspects. See Table 2.

\section{Hand Strength}

One trial showed significant differences in the mean changes in both sided maximum and one-sided final grip force, as measured with Grippit. Some improvements were also sustained at the 6-month follow-up (21). In the grip-pinch test, one trial showed that the strength of the nondominant hand significantly increased (15). Two trials showed no significant differences were observed for the group comparisons after treatment or at followup $(17,18)$.

\section{Range of Joint Motion}

Only one trial showed that the ROM (shoulder, elbow joint, and hip joint flexion) on the affected side of subjects in the experimental group was increased following the music therapy, whereas the ROM of these joints in the control group either decreased or remained the same. There was a significant increase in shoulder flexion and elbow joint flexion (18).

\section{Dexterity of Hands}

Five trials with nine-hole peg test examined fine motor skills of hands improved gradually $(9,15,16,19,22)$. One trial showed no significant differences were observed for the group comparisons after treatment or at follow-up; however, the withingroup analyses revealed that both groups improved after and at follow-up using nie-hole peg test and box and blocks test (17). In the test of finger tapping measurements, there was no significant difference between groups in areas of tapping speed and variability (19).

\section{Arm Function}

Significant improvements in motor functions of upper limbs after 4 weeks of treatment; however, we only found differences between the two groups in Wolf motor function test (WMFTquality: $p=0.025$; WMFT-time: $p=0.037)$, but found no differences in Fugl-Meyer assessment $(p=0.448)$ (12). GrauSanchez's (17) study showed that in 39 included patients, no significant difference between MST groups and control groups was shown after a 4 -week treatment. Four trials showed no significant difference between groups in arm function through the action research arm test $(9,16,17,23)$. One of the four trials found the within-group analyses revealed that both groups improved after and at follow-up (17). Another trial also indicated minor changes by the CMSA arm and hand impairment scale (23). However, MST patients in one trial showed a substantial improvement over time compared with other groups of patients in the action research arm test and arm paresis score (22). One trial also did not produce any immediate gains with the Modified Motor Assessment Scale (M-MAS) (24).

\section{Activities of Daily Living}

No significant differences in effect using Chedoke Arm and Hand Activity Inventory (CAHAI) or Korean-modified Barthel index (K-MBI) $(18,19)$. Only one trial showed significantly improved $\mathrm{ADL}$ score in the recovery group compared with the no-recovery group (20).

\section{Quality of Life}

One trial showed a significant positive trend in quality of life through the Italian version of McGill Quality-of-Life Questionnaire (MQOL-It), but no clinical differences between groups were found (15). There was a significant improvement in the MST group from baseline to posttreatment compared with the conventional treatment groups among other trials (17). Negative effect of affective functions and quality of life was significantly reduced after intervention (23). 
TABLE 2 | The result of outcome measures in the included studies.

\begin{tabular}{|c|c|c|}
\hline Outcome measures & Measurements & Results \\
\hline \multirow[t]{3}{*}{ Muscle strength } & Grippit & $\begin{array}{l}\text { Improvements were shown at the final of intervention and 6-month } \\
\text { follow-up (21) }\end{array}$ \\
\hline & Grip-pinch test & Strength of nondominant hand significantly increased (15) \\
\hline & Medical Research Council scale and grip strength & No significant difference between groups $(17,18)$ \\
\hline Range of joint motion & Measuring the ROM of shoulder, elbow joint, and hip joint flexion & Significant increase in shoulder flexion and elbow joint flexion (18) \\
\hline \multirow[t]{3}{*}{ Dexterity of hands } & 9-Hole peg test & Improved gradually $(9,15,16,19,22)$ \\
\hline & 9-Hole peg test and box and blocks test & Both groups improved but no significant differences (17) \\
\hline & Test of finger tapping measurements & No significant difference between groups (19) \\
\hline \multirow[t]{4}{*}{ Arm function } & Wolf motor function test & Significant differences between the 2 groups (12) \\
\hline & The action research arm test and arm paresis score & Significant differences between the 2 groups (22) \\
\hline & The action research arm test & No significant difference between groups $(9,16,17,23)$ \\
\hline & The Modified Motor Assessment Scale (M-MAS) & No significant difference between groups (24) \\
\hline \multirow[t]{2}{*}{ Activities of daily living } & The Barthel Index & Significant differences between the two groups (20) \\
\hline & $\begin{array}{l}\text { Chedoke Arm and Hand Activity Inventory (CAHAl) or } \\
\text { Korean-modified Barthel index (K-MBI) }\end{array}$ & No significant difference between groups $(18,19)$ \\
\hline \multirow[t]{2}{*}{ Quality of life } & $\begin{array}{l}\text { The Stroke-Specific QoL Scale and health-related QoL with the } \\
\text { health survey questionnaire SF36 }\end{array}$ & Significant differences between the 2 groups (17) \\
\hline & Italian version of McGill Quality-of-Life Questionnaire (MQOL-It) & No significant difference between groups (15) \\
\hline
\end{tabular}

\section{DISCUSSION}

The purpose of this systematic review was to evaluate the effectiveness of MST on hand function improvement in stroke patients. The result shows that MST can be useful in improving hand function and the quality of life in stroke patients.

The subjects of studies we focus are symptoms of unilateral hemiparesis in ischemic and hemorrhagic stroke patients. Through a systematic review, we found that MST can improve hand function in patients. Especially for patients within 6 months after stroke, MST can significantly improve their hand function with different aspects such as dexterity of hands.

However, according to the included studies, only a few studies have clear results indicating that the grasping ability and the dexterity of the finger are improved $(9,15,16,19,22)$. For example, one study stated that the hand function was improved for both the MST group and the control group, but there were no significant differences between the two groups when compared (15). MST did not show superiority improvement when compared with conventional therapy. At this point, we conclude that it may be caused by the following reasons. Firstly, low-intensity music-supported therapy is not known to cause an effect on the improvement of a patient's ability. Therefore, according to the results of a systematic review, training for at least $30 \mathrm{~min}$ a day and five times a week is the suitable intensity that is proven as effective. Secondly, some assessment scales, such as FMA, are not sensitive enough to assess the difference in the area of hand function before and after treatment, while assessment scales like WMFT can. The reasons may be because the movement of MST is similar to the movement of evaluation so that it causes some bias that impacts the result of the assessment. Therefore, when we select the assessment scale, we should choose an appropriate scale that can have a good sensitivity to identify the differences. Finally, several studies stated that for their research, the sample size was not large enough to obtain a significantly different result, which suggests that we should do a larger experiment to show the effect of music-supported therapy in the future.

Among the included studies, MST has been described to improve hand function. Compared with traditional treatment, the patient mainly improved the ability of priming, timing, trajectory, and muscle force requirements for the movements of the upper limbs (16), and because of the characteristics of MST, such as, noninvasive, low cost, convenient, and effective intervention, it has been widely used in practice and accepted by Chinese occupational therapists. When playing a musical instrument, the hands follow the beat of the music and make corresponding movements, which is a kind of stimulation to the damaged part of the brain (25). The musical stimulation can promote the extensive activation of the patient's central nervous system' functional network, increase blood flow in the brain area, and accept more stimulation from the movement (26, 27). Among the included articles, there are descriptions of the use of violin, piano, and drumming instruments for treatment. When the patient's hand grasps or strikes the instruments, the patient's grasping ability can be trained purposefully. When the stroke patients train with the rhythm of music, it can help muscle contraction to become more active, so that the sense of participation, rhythm, and speed in the exercise will be more effective (28).

MST can have an improved performance in activities of daily living and enhance the quality of life (17). Furthermore, MST decreases a patient's depression and helps deal with the emotional stress caused by sudden and severe neurological diseases (19). MST helps the patient facilitate their emotions and share their feelings. At the same time, music also plays an important role in motivating patients and stimulating their inner motivation. MST 
increases patients' motivation due to happiness and intrinsic motivation. We can help them acquire a new skill as well as a hobby so that they can actively participate in MST and enjoy the fun of playing.

\section{LIMITATIONS}

The systematic review has some limitations that should be given attention. First, the sample size in the study is not big enough. Studies with larger sample sizes are needed in the coming future. Second, when conducting a systematic search of the literatures, only studies written in English were searched. It is possible that we missed articles of high significance written in other languages. Third, there was a lack of good way of randomization in the included studies, especially with the blinding of patients. It is clear that patients had knowledge of whether they were receiving MST or not, so there was an inability to avoid a placebo effect as a result of receiving MST. Higher-quality articles are needed to provide ideas on how to avoid the placebo effect, and it will be applied for future research development.

\section{CONCLUSION}

The review included data from 12 randomized controlled trials to explore the effectiveness of MST on the hand function for patients

\section{REFERENCES}

1. Luo Z, Zhou Y, He H, Lin S, Zhu R, Liu Z, et al. Synergistic effect of combined mirror therapy on upper extremity in patients with stroke: a systematic review and meta-analysis. Front Neurol. (2020) 11:155. doi: 10.3389/fneur.2020.00155

2. Wu S, Wu B, Liu M, Chen Z, Wang W, Anderson CS, et al. Stroke in China: advances and challenges in epidemiology, prevention, and management. Lancet Neurol. (2019) 18:394-405. doi: 10.1016/S1474-4422(18)30500-3

3. Behrendt F, Rizza JC, Blum F, Suica Z, Schuster-Amft C. German version of the Chedoke McMaster arm and hand activity inventory (CAHAI-G): intrarater reliability and responsiveness. Health Qual Life Outcomes. (2020) 18:1-9. doi: 10.1186/s12955-020-01499-6

4. Samuelkamaleshkumar S, Reethajanetsureka S, Pauljebaraj P, Benshamir B, Padankatti S, David J. Mirror therapy enhances motor performance in the paretic upper limb after stroke: a pilot randomized controlled trial. Arch Phys Med Rehabil. (2014) 95:2000-5. doi: 10.1016/j.apmr.2014.06.020

5. Lim KB, Lee HJ, Yoo J, Yun HJ, Hwang HJ. Efficacy of mirror therapy containing functional tasks in poststroke patients. Ann Rehabil Med. (2016) 40:629-36. doi: 10.5535/arm.2016.40.4.629

6. Kwakkel G, Veerbeek JM, van Wegen EE, Wolf SL. Constraint-induced movement therapy after stroke. Lancet Neurol. (2015) 14:224-34. doi: 10.1016/S1474-4422(14)70160-7

7. Park JY, Chang M, Kim KM, Kim HJ. The effect of mirror therapy on upperextremity function and activities of daily living in stroke patients. J Phys Ther Sci. (2015) 27:1681-3. doi: 10.1589/jpts.27.1681

8. Zhang Y, Cai J, Zhang Y, Ren T, Zhao M, Zhao Q. Improvement in strokeinduced motor dysfunction by music-supported therapy: a systematic review and meta-analysis. Sci Rep. (2016) 6:38521. doi: 10.1038/srep38521

9. Street AJ, Magee WL, Odell-Miller H, Bateman A, Fachner JC. Home-based neurologic music therapy for upper limb rehabilitation with stroke patients at community rehabilitation stage-a feasibility study protocol. Front Hum Neurosci. (2015) 9:480. doi: 10.3389/fnhum.2015.00480 after stroke. Based on current evidence, this study demonstrated that MST can improve hand function and enhance a patient's quality of life. The rhythm and auditory feedback play a vital part in the treatment of MST. However, more well-described randomized controlled trials are required to prove its efficacy.

\section{DATA AVAILABILITY STATEMENT}

The raw data supporting the conclusions of this article will be made available by the authors, without undue reservation.

\section{AUTHOR CONTRIBUTIONS}

W-HH, Z-LD, H-MJ, YC, XL, and QZ worked together to complete the manuscript. Z-LD and H-MJ assisted W-HH in document retrieval and screening. YC provided statistical assistance and support. XL and QZ provided opinions on grammar and rhetoric. All authors contributed to the article and approved the submitted version.

\section{FUNDING}

This work was supported by the Key R\&D Program of Guangdong Province, China under grant 2018B030339001.

10. Särkämö T, Soto D. Music listening after stroke: beneficial effects and potential neural mechanisms. Ann N Y Acad Sci. (2012) 1252:266-81. doi: 10.1111/j.1749-6632.2011.06405.x

11. Cramer SC, Sur M, Dobkin BH, O’Brien C, Sanger TD, Trojanowski JQ, et al. Harnessing neuroplasticity for clinical applications. Brain. (2011) 134:1591609. doi: 10.1093/brain/awr039

12. Tong Y, Forreider B, Sun X, Geng X, Zhang W, Du H, et al. Musicsupported therapy (MST) in improving post-stroke patients' upper-limb motor function: a randomised controlled pilot study. Neurol Res. (2015) 37:434-40. doi: 10.1179/1743132815Y.0000000034

13. Ghai S, Ghai I. Effects of (music-based) rhythmic auditory cueing training on gait and posture post-stroke: a systematic review and dose-response meta-analysis. Sci Rep. (2019) 9:2183. doi: 10.1038/s41598-019-38723-3

14. Hariton E, Locascio JJ. Randomised controlled trials-The gold standard for effectiveness research. BJOG. (2018) 125:1716. doi: 10.1111/1471-0528.15199

15. Raglio A, Zaliani A, Baiardi P, Bossi D, Sguazzin C, Capodaglio E, et al. Active music therapy approach for stroke patients in the post-acute rehabilitation. Neurol Sci. (2017) 38:893-7. doi: 10.1007/s10072-017-2827-7

16. Street AJ, Magee WL, Bateman A, Parker M, Odell-Miller H, Fachner J. Homebased neurologic music therapy for arm hemiparesis following stroke: results from a pilot, feasibility randomized controlled trial. Clin Rehabil. (2018) 32:18-28. doi: 10.1177/0269215517717060

17. Grau-Sanchez J, Ramos-Escobar N, Sierpowska J, Rueda N, Susana R, Rifà $\mathrm{X}$, et al. Music-supported therapy in the rehabilitation of subacute stroke patients: a randomized controlled trial. Ann N Y Acad Sci. (2018) 61:e191. doi: 10.1016/j.rehab.2018.05.438

18. Jun EM, Roh YH, Kim MJ. The effect of music-movement therapy on physical and psychological states of stroke patients. J Clin Nurs. (2013) 22:22-31. doi: 10.1111/j.1365-2702.2012.04243.x

19. Van Vugt FT, Kafczyk T, Kuhn W, Rollnik JD, Tillmann B, Altenmüller E. The role of auditory feedback in music-supported stroke rehabilitation: a singleblinded randomised controlled intervention. Restor Neurol Neurosci. (2016) 34:297-311. doi: 10.3233/RNN-150588 
20. Fotakopoulos G, Kotlia P. The value of exercise rehabilitation program accompanied by experiential music for recovery of cognitive and motor skills in stroke patients. J Stroke Cerebrovasc Dis. (2018) 27:2932-9. doi: 10.1016/j.jstrokecerebrovasdis.2018.06.025

21. Bunketorp-Käll L, Lundgren-Nilsson Å, Samuelsson H, Pekny T, Blomvé K, Pekna $\mathrm{M}$, et al. Long-term improvements after multimodal rehabilitation in late phase after stroke: a randomized controlled trial. Stroke. (2017) 48:191624. doi: 10.1161/STROKEAHA.116.016433

22. Schneider S, Müünte T, Rodriguez-Fornells A, Sailer M, Altenmüüller E. Music-supported training is more efficient than functional motor training for recovery of fine motor skills in stroke patients. Music Percept. (2010) 27:271-80. doi: 10.1525/mp.2010.27.4.271

23. Fujioka T, Dawson DR, Wright R, Honjo K, Chen JL, Chen JJ, et al. The effects of music-supported therapy on motor, cognitive, and psychosocial functions in chronic stroke. Ann N Y Acad Sci. (2018) 1423:264-74. doi: 10.1111 /nyas. 13706

24. Bunketorp-Käll L, Pekna M, Pekny M, Blomstrand C, Nilsson M. Effects of horse-riding therapy and rhythm-and music based therapy on functional mobility in late phase after stroke. NeuroRehabilitation. (2019) 45:483-92. doi: 10.3233/NRE-192905

25. Neugebauer CT, Serghiou M, Herndon DN, Suman OE. Effects of a 12-week rehabilitation program with music and exercise groups on range of motion in young children with severe burns. J Burn Care Res. (2008) 29:939-48. doi: 10.1097/BCR.0b013e31818b9e0e

26. Jäncke L. Music, memory and emotion. J Biol. (2008) 7:1-5 doi: $10.1186 /$ jbiol 82

27. Karmonik C, Brandt A, Anderson JR, Brooks F, Lytle J, Silverman E, et al. Music listening modulates functional connectivity and information flow in the human brain. Brain Connect. (2016) 6:632-41. doi: 10.1089/brain.2016.0428

28. Biasutti M, Mangiacotti A. Assessing a cognitive music training for older participants: a randomised controlled trial. Int J Geriatr Psychiatry. (2018) 33:271-8. doi: 10.1002/gps.4721

Conflict of Interest: The authors declare that the research was conducted in the absence of any commercial or financial relationships that could be construed as a potential conflict of interest.

Copyright (C) 2021 Huang, Dou, Jin, Cui, Li and Zeng. This is an open-access article distributed under the terms of the Creative Commons Attribution License (CC BY). The use, distribution or reproduction in other forums is permitted, provided the original author(s) and the copyright owner(s) are credited and that the original publication in this journal is cited, in accordance with accepted academic practice. No use, distribution or reproduction is permitted which does not comply with these terms. 